\title{
Why are we not always witnessing a take-off of the Moroccan cooperative model?
}

\author{
Malak Bouhazzama ${ }^{1}$, Mssassi Said $^{2}$ \\ ${ }^{I}$ National school of management, AbdelmalekEssaadi University, Tangier, Morocco \\ ${ }^{2}$ National school of management, AbdelmalekEssaadi University, Tangier, Morocco \\ malak.bouhazzama.encgt@gmail.com
}

Keywords: Benchmarking, cooperative, stakeholders, Public policies, Morocco.

Abstract: In a context of globalization, the capitalist economy is no longer immune to the deluge of crises that have followed one another since the crisis subprime in the United States until the Japanese stock market crisis influencing the global economic fabric.Thus, several countries with great economic strength like France have turned to the social and solidarity economy as an alternative banning the single search for financial gain by introducing additional social and environmental components.At this advanced stage and after 10 years of launching the INDH in its second phase, why associations and cooperatives still do not manage to be autonomous, responsible and independent? Why the various training, support and communication actions remain inefficient and inoperative? Why several projects that have emerged are still overdue despite the availability of financial funds? Why is Morocco still not witnessing the emergence of this great economic model?

\section{Introduction:}

The Social and Solidarity Economy brings together a set of structures that are based on common values and principles: social utility, cooperation, local anchoring adapted to the needs of each territory and its inhabitants. Their activities are not aimed at personal enrichment but at sharing and solidarity for an economy respectful of man and his environment. The economic model of the ESS is at the service of society and the citizen.

In Morocco, the National Initiative for Human Development comes to crown the values and principles of the social and solidarity economy on the base a global and integrated vision of social and human development with the aim of combating the social deficits which continue to plague society and to lay the foundations for the harmonious development of towns and the countryside. It also proposes to strengthen the action of the State and local communities without replacing sectoral programs or Economic and Social Development Plans of local communities.

To this end, it offers additional financing capacity to support actions allowing rapid and sustainable growth of human development indices to appreciable levels. Its implementation places the fight against poverty, exclusion and precariousness at the center of the country's economic and social policy priorities, and is the result of a decentralized approach based on targeting the geographical areas and the most deprived categories. as well as on the principles 
of effective participation of beneficiary populations, strategic planning, partnership with local actors to ensure better ownership and sustainability of projects and interventions and their convergence with current sectoral programs.

However and despite the efforts made by several organizations to ensure the proper functioning of this development wheel such as the Social Action Division (DAS) of the provinces, ADS, ODECO ... alongside the various non-governmental organizations that plead for SSE as well as for the impregnation of these principles in the form of training, communication and support actions. The associative fabric and cooperatives still do not assimilate the heart of the NHRI's philosophy which is essentially based on taking the initiative and continues to face difficulties related to the management and especially to the marketing of products. final. At this stage, we try to ask several questions: Is it a simple lack of funds? Is it linked to a crisis of values? What are the difficulties facing cooperatives? support and communication remain inefficient and not very operational? why several projects that have emerged are still overdue despite the availability of financial funds? Why is Morocco still not witnessing the emergence of this great economic model? Is it a simple lack of funds? Is it linked to a crisis of values? What are the difficulties facing cooperatives? support and communication remain inefficient and not very operational? why several projects that have emerged are still overdue despite the availability of financial funds? Why is Morocco still not witnessing the emergence of this great economic model? Is it a simple lack of funds? Is it linked to a crisis of values? What are the difficulties facing cooperatives?

Nowadays, cooperatives play a major role in the development of Morocco. And this, by creating wealth and employment for a vulnerable social layer. These cooperatives have long benefited from a great economic boom. This is the reason why the Office for the Development of Cooperation (ODCO) in 1963 was created structured in 1975 to raise awareness and monitor cooperatives in their economic, social and ecological projects aimed at fighting poverty and insecurity. This push given to cooperatives was consolidated with the establishment of the National Human Development Initiative (INDH), which was launched between 2005 and 2015 in two distinct phases. In addition, in a framework characterized by progressive economic development and by increased or even fierce competition, all cooperatives are required to review the way they market their products. This is the reason why a marketing structure remains a condition for cooperatives in order to anticipate the environment and maintain their places in the market. 
Dn the movement of the constitutional change of 2011, Morocco has initiated several projects: reform of the legal framework, upgrading and strengthening of the capacities of SSE organizations, support for marketing, etc. On the legislative side, laws relating to cooperatives, fair trade and associations have been adopted or are under study. A framework law on the social economy was also announced, this new law n ${ }^{\circ} 112-12$ (Published in Official Bulletin $n$ ${ }^{\circ} 6318$ of December 18, 2014) allowed:

1- A precise definition of cooperative activity as "a group of natural or legal persons, who agree to meet to create a business", (article 1) and the adoption of the 7 cooperative principles recognized worldwide by the International Cooperative Alliance in 1995;

2- The simplification of the procedure for the constitution of cooperatives Simplification of the by reducing the number of members from 7 to 5 as well as the obligation to obtain authorization will be abolished;

3- The abolition of the authorization prior to the exercise, of the territorial constituency and of the permanent advisory committee and opening of the possibility of submission to public contracts to cooperatives.

4- Strengthening transparency and promoting good governance through rigor in the discipline of general assemblies and compliance with the laws in force, including those that impose fines and sanctions on anyone who violates or violates by the compulsory keeping of three registers at the headquarters of the cooperative: - Registers of members of the cooperative - Register of minutes of meetings of the board of directors, - Register of minutes of meetings of general assemblies;

5- The possibility for legal persons to join cooperatives, however The articles of association set the maximum amount of shares that can be held by cooperative members who are legal persons. However, the share of individual cooperative members must in no case be less than $65 \%$ of the cooperative's capital;

6- The setting of the minimum capital threshold at 1,000 DH in order to materialize the desire to work together among the cooperators and distribution of the cooperative's surpluses among all the members of the cooperative up to the level of the work they have done;

7- A new articulation in the functioning of the various bodies of the cooperative and creation of a national register of cooperatives and local registers of registration;

8- A better definition of the responsibility of the governing bodies for example A cooperative with less than 50 members can create the position of manager, while cooperatives with a turnover of more than 5 million dirhams can be managed by a board of administration;

9- Better sustainability of relationships and strengthening of trust through the 
establishment of a conciliation and dispute settlement procedure under the aegis of cooperative unions or the national cooperative federation. 
The first comprehensive and unified law for the Moroccan cooperative movement was Law 24-83 in 1983 and only saw the light of day in 1993 and was repealed by Law 112-12 relating to cooperatives and then implemented in 2016. Indeed, the Moroccan public authorities aim by this law to revitalize cooperatives by better integration into the market economy and an effective contribution to the development of the national economy in a framework favorable to the development of the cooperative and solidarity spirit based on justice, equity and democracy and likely to mobilize resources and energies for integrated and sustainable actions.

Fromis the promulgation of law 112-12 relating to cooperatives in 2014 to reach at the end of 2019, 27.262 and thanks to the simplification of procedures and the advantages offered by the government to the Moroccan cooperative sector, the frequency of creation of cooperatives according to ODECO has grown remarkably to 6,000 naming requests in a span of six months. On the other hand, this phenomenon is explained by the reservation of municipal councils, provincial councils and regional councils of special budgetary chapters to encourage the constitution of cooperatives in order to reduce unemployment and integrate women into the economic fabric. local or regional by creating regional social and solidarity economy observatories in order to provide training and modernize management,

Indeed, the public authorities presented various privileges and financial incentives in order to promote the creation of new forms of grouping such as professional associations, economic interest groups (GIE), inter-branch organizations, especially in the agricultural sector to resolve the marketing problem and valuation of the product of cooperatives. At the same time, ODCO also organized awareness-raising and popularization campaigns through its program entitled "Mourafaka" dedicated to newly created cooperatives in post-creation in order to improve their income and make them sustainable as well as to promote local products for around 200,000 direct and indirect beneficiaries without forgettingthe programs of the National Agricultural Advisory Board (ONCA) aimed at grouping small farmers into cooperatives have been a large-scale initiative for the development of the agricultural sector in particular: The agricultural cooperative sector is the most dominant with 17,582 cooperatives and 406,542 cooperative members according to ODECO in 2019.

Thes cooperatives were formed mainly in the sectors of agriculture, crafts, Habitat, forests,pmedicinal and aromatic plants (PAM), argan, transport, fishing, literacy, foodstuffs, art and culture, quarrying, consumption, advice and management, labor, retail traders, mining, telecommunications, tourism, waste treatment, printing - stationery, electronic commerce, etc. Moreover, the number of $100 \%$ female cooperatives rose to 3,520 cooperatives at the end of 
2019 , bringing together 46,384 members with an increase of 1,240 female cooperatives during the last four years, i.e. $10 \%$ of newly created cooperatives.

NOTNevertheless, it should be emphasized that the general notion of social and solidarity economy remains relatively poorly defined and little known in Morocco. It is often drowned in a vague concept encompassing small producers, crafts, cooperatives, associations, mutuals... If we exclude the direct actors of the sector, it remains manifestly unrecognized by a large part of the population, even among several decision-makers and officials of the administration.

Lhe national strategy for the social and solidarity economy (2010-2020) defines the social and solidarity economy as "all economic initiatives seeking to produce goods or services, to consume and save differently, in a more respectful manner of Man, the environment and territories "(p. 28). The list of sectors covered by SSE organizations is varied: agriculture, crafts, real estate, tourism, forestry, financial services, health and social services, employment integration, education, cultural activities ... and the report identifies several possible structures: "Depending on the mode of organization, these initiatives are generally carried out within the framework of: cooperatives, associations, mutual societies, foundations, or any other type of organization respecting the values of the social economy. Businesses, particularly VSEs, which focus on integration through economic activity allowing unemployed people, encountering particular social and professional difficulties, to benefit from a job in order to facilitate their professional integration. " (p.28 of the report), but if an inventory of local authorities, associations and mutuals is drawn up in the remainder of the report, social enterprises, for their part, seem to have been forgotten. to benefit from a job in order to facilitate their professional integration. " (p.28 of the report), but if an inventory of local authorities, associations and mutuals is drawn up in the remainder of the report, social enterprises, for their part, seem to have been forgotten. to benefit from a job in order to facilitate their professional integration. " (p.28 of the report), but if an inventory of local authorities, associations and mutuals is drawn up in the remainder of the report, social enterprises, for their part, seem to have been forgotten.

Nevertheless, these multiple achievements of ODECO were only possible thanks to the signing of conventions with the following partners:

- The National Human Development Initiative (INDH) forfight against poverty and social exclusion. 
- the Social Development Agency (ADS) for assistance to the promoters of IGA projects.

- The national agency for the promotion of employment and skills (ANAPEC) for the encouragement of cooperatives.

- Mohamed V Foundation for the marketing of local products and those of cooperatives

- The national agency for aromatic and medicinal products $\mathrm{p}$ in the aromatic and medicinal products sector by 2022 .

- Universities to coordinate research and promote cooperative management.

- Mohamed V Foundation for the marketing of local products and those of cooperatives

- The Ministry of Handicrafts and Social and Solidarity Economy as part of the enhancement of the production chain and marketing of cooperative products.

\section{Methodology :}

Our study aims to question the Moroccan cooperative take-off as a lever for sustainable development. We opted for a quantitative methodology using a questionnaire with a sample of 100 cooperatives scattered throughout the country carrying out various activities. However, this approach was supplemented by a qualitative approach via semi-structured interviews carried out with a limited sample of 30 cooperatives making

Table 1: list of cooperatives subject to qualitative study

\begin{tabular}{|l|l|c|l|c|}
\hline cooperatives & Categories & $\begin{array}{c}\text { Number of } \\
\text { members }\end{array}$ & city & $\begin{array}{c}\text { year of } \\
\text { creationcreation }\end{array}$ \\
\hline cooperative 1 & Agriculture & 30 & El Kelaâ Des & 2007 \\
\hline
\end{tabular}




\begin{tabular}{|c|c|c|c|c|}
\hline cooperative 2 & $\begin{array}{l}\text { Aromatic and } \\
\text { medicinal plants }\end{array}$ & 70 & Ouezzane & 2016 \\
\hline cooperative 3 & Beekeeping & 80 & Ouarzazate & 2009 \\
\hline cooperative 4 & Argan & 90 & Taroudant & 206 \\
\hline cooperative 5 & Agriculture & 20 & Beni Mellal & 2005 \\
\hline cooperative 6 & Traditionalsewing & 25 & El Jadida & 2015 \\
\hline cooperative 7 & Weaving & 16 & Azilal & 2003 \\
\hline cooperative 8 & Foodstuffs & 30 & Rabat & 2010 \\
\hline cooperative 9 & Beekeeping & 15 & Sefrou & 2011 \\
\hline cooperative & Seafishing & 45 & Boujdour & 2007 \\
\hline cooperative & Agriculture & 50 & Sidi Kacem & 2008 \\
\hline cooperative & Traditionalsewing & 9 & Meknes & 2010 \\
\hline cooperative & Arts and crafts & 13 & Safi & 2014 \\
\hline cooperative & Aromatic and & 11 & Midelt & 2014 \\
\hline cooperative & Agriculture & 50 & Taroudant & 2010 \\
\hline cooperative & Agriculture & 19 & Sefrou & 2009 \\
\hline cooperative & Agriculture & 37 & Tinghir & 2006 \\
\hline cooperative & Beekeeping & 25 & Sidi Slimane & 2010 \\
\hline cooperative & Arts and crafts & 30 & Fes & 2011 \\
\hline cooperative & Weaving & 70 & Ouazzane & 2012 \\
\hline cooperative & Agriculture & 36 & El Youssoufia & 2017 \\
\hline cooperative & \begin{tabular}{|l|} 
Agriculture \\
\end{tabular} & 11 & El Kelaâ Des & 2010 \\
\hline cooperative & Alphabetization & 15 & Safi & 2013 \\
\hline cooperative & Arts and crafts & 25 & Chichaoua & 2010 \\
\hline cooperative & Habitat & 10 & Tiznit & 2018 \\
\hline cooperative & Agriculture & 61 & Errachidia & 2018 \\
\hline cooperative & Agriculture & 80 & Aunty & 2011 \\
\hline cooperative & Weaving & 30 & Ouazzane & 2015 \\
\hline cooperative & Traditionalsewing & 23 & Rabat & 2018 \\
\hline cooperative & Aromatic and & 49 & Oujda & 2009 \\
\hline
\end{tabular}

\section{Source:author'selaboration}

This study allows us to draw an image on the Moroccan cooperative management as well as the obstacles facing these structures by highlighting the problems and obstacles encountered throughout the process of creation and establishment and positioning in national and international markets. We completed our quantitative survey with another qualitative one through face-to-face interviews with representatives of the cooperatives. Indeed, the questionnaires and interviews were centered around three main axes:

- General information on cooperatives.

- Problems facing cooperatives, mainly those related to: a- Operational marketing of cooperatives: product, price, distribution and communication, bFunding resources and support programs, c- Capacity building and training engineering for cooperatives, $d$ - Governance and management methods of 
cooperators.

- $\quad$ Proposals and avenues for improvement for the emergence of the Moroccan cooperative model.

\section{Analysis and discussion of results}

Before starting our analysis, it is more constructive to focus on the characteristics of the hundred cooperatives studied. First of all, in terms of their geographical distribution, we tried to choose cooperatives throughout the Moroccan territory from north to south and from east to west, as to the sectors of activity of the cooperatives of this sample $56 \%$ are agricultural cooperatives, $25 \%$ are artisanal, $12 \%$ are commercial cooperatives, $4 \%$ literacy, $2 \%$ sea fishing, and finally $1 \%$ in food. The number of co-operators within the co-operatives varied between 9 and 210 people. Finally, with regard to the gender of cooperative presidents, $84 \%$ are men and $16 \%$ are women.

In order to draw up a national strategy, $85 \%$ of respondents believe that government policies are essentially the key to the success of cooperatives as well as the economic, social and ecological environments. Indeed, $76 \%$ of the cooperatives questioned declared having benefited from at least one financing program and one training or support action. However, they consider the constant support of the State and the promotion of these programs to be necessary in order to benefit more especially from the financial aspect. This aspect is very important for the sustainability of companies because $98 \%$ declared that their main problem is financial,

These Results prompted us to dig further through the qualitative study as the quantitative study showed amazing results. For example, concerning the Marketing policy, $73 \%$ of respondents indicated that cooperatives carry out a market and economic environment study before proceeding with the creation of their cooperative or the launch of a new product, however, when of semi-structured interviews only $21 \%$ carried out this type of commercial study or the realization of a business plan or a commercial policy. Finally, in terms of governance and cooperative management methods, all cooperatives unanimously declared that they respect universal cooperative principles, which prompted us to focus on this point, which can be the keystone of this study. Indeed,

\section{$\underline{\text { Conclusion }}$}

Today, the challenge for cooperatives in Morocco is to go beyond the simple response 
formulated in an emergency to precarious conditions in a coherent and articulated manner. It emerges from this observation a very fragmented image of SSE dynamics due to the observed structural weakness of activities leading to difficulties in perpetuating and institutionalizing as well as playing the role of interlocutor at the local, regional or national level. this contrasts with the image observed in Europe and in certain countries of North or South America where the concept of Social and Solidarity Economy is intended to respond to a wider field of societal needs. Contrary to the image conveyed at the national level, this mixed study generated breathtaking results, financial and commercial problems are omnipresent, but the real problem that must be emphasized is that of the governance of cooperatives. Indeed, the focus on this component will allow the creation of wealth for the local community and the realization of profits for the cooperators by the promotion of local products which will generate national economic growth by the export of local products. On the other hand, the emergence of the cooperative sector will make it possible socially to fight against unemployment, illiteracy and poverty and preservation of the environment through the use of organic raw materials. the focus on this component will allow the creation of wealth for the local community and the realization of profits for the cooperators through the promotion of local products which will generate national economic growth through the export of local products. On the other hand, the emergence of the cooperative sector will make it possible socially to fight against unemployment, illiteracy and poverty and preservation of the environment through the use of organic raw materials. the focus on this component will allow the creation of wealth for the local community and the realization of profits for the cooperators through the promotion of local products which will generate national economic growth through the export of local products. On the other hand, the emergence of the cooperative sector will make it possible socially to fight against unemployment, illiteracy and poverty and preservation of the environment through the use of organic raw materials. 